\title{
Significant changes between the ISCCP C and D cloud climatologies
}

\author{
Marie Doutriaux-Boucher \\ Laboratoire d'Optique Atmosphérique, Université de Lille I, Villeneuve d'Ascq, France
}

Geneviève Sèze

Laboratoire de Météorologie Dynamique, Université Paris VI, Paris, France

\begin{abstract}
We analyse one year of cloud data from the ISCCP C and D datasets. The two datasets differ by their retrieval algorithms and their definitions of the cloud types defined from the cloud top pressure and cloud optical depth. The differences between the two datasets are first described in terms of the total cloud cover, as well as its repartition in low, middle, and high level cloudiness. We also project the ISCCP C cloud classes into the ISCCP D cloud types to circumvent the problem of different cloud type definitions in the two datasets. The differences between the two datasets are then also investigated in terms of the most frequent cloud type.
\end{abstract}

\section{Introduction}

The importance of clouds in climate has long been recognized and long-term observations are needed to monitor changes in cloud cover and cloud properties [Rossow and Cairns, 1995]. The International Satellite Cloud Climatology Project (ISCCP) provides information on the spacetime characteristics of clouds, such as cloud amount, cloud top pressure, and cloud optical depth [Schiffer and Rossow, 1983; Rossow and Schiffer, 1991]. These characteristics inferred from the visible and infrared radiances measured by radiometers on various satellites allow clouds to be classified into cloud types (e.g., stratus, cumulus, cirrus). The initial $\mathrm{C}$ cloud product is now replaced by the improved $D$ cloud product through the reprocessing of the entire ISCCP dataset. The purpose of this note is to point out some resemblances and differences between the $C$ and D cloud products.

\section{The ISCCP Algorithms}

For details of the $\mathrm{C}$ algorithm, the reader is directed to Rossow and Schiffer [1991] and Rossow et al. [1991]. The statistics for cloud properties are gathered every 3 hours on an equal area grid. During daytime, visible and infrared radiances are available and cloudy scenes are divided into 35 cloud classes according to cloud top pressure and cloud optical depth, leading to the cloud types shown in Fig. 1a (two types for low level clouds, two types for middle level clouds, and three types for high level clouds). The ISCCP C dataset is available from July 1983 to June 1991. Comparison of

Copyright 1998 by the American Geophysical Union.

Paper number 1998 GL900081.

0094-8276/98/1998GL900081\$05.00 the ISCCP C cloud amounts with surface observations evidenced a lack of cloudiness over land as well as in polar regions [Rossow et al., 1993]. The SAGE II results further showed that thin high level clouds were missed by ISCCP [Liao et al., 1995]. Improvements and refinements in the algorithm led to the ISCCP D cloud products. Differences between the $\mathrm{C}$ and $\mathrm{D}$ algorithms include more accurate radiometric calibrations, improvements in cloud detection (lower infrared (IR) threshold for cirrus detection over land, lower visible (VIS) threshold for cloud detection over ice and snow surfaces and use of a threshold test on the $3.7 \mu \mathrm{m}$ radiances, and improved detection of low clouds at high latitudes by changing to a VIS reflectance threshold test), and improvements in the radiative transfer model [Rossow et al., 1996]. Improvements in the radiometric calibrations [Brest et al., 1997] were necessary in view of the long-term trends in cloud optical depth and cloud top temperature observed by Klein and Hartmann [1993] and in order to eliminate changes between different reference polar orbiters.

Differences in the $\mathrm{C}$ and $\mathrm{D}$ algorithms also include changes in the definition of cloud classes. The last range of cloud optical depth $(\tau=23-125)$ is replaced by two ranges $(\tau=23-60$ and $\tau=60-379$ ) leading to 42 cloud classes. The number of cloud types is increased from 7 to 9 ( 3 types for low, middle, and high level clouds) (Fig. 1b). The $\mathrm{C}$ stratus type is divided into a $\mathrm{D}$ stratus type and a stratocumulus type. The altostratus cloud type separates the former $\mathrm{C}$ altocumulus

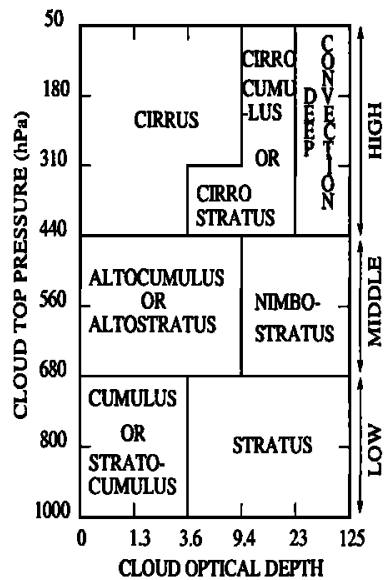

(a) ISCCP C

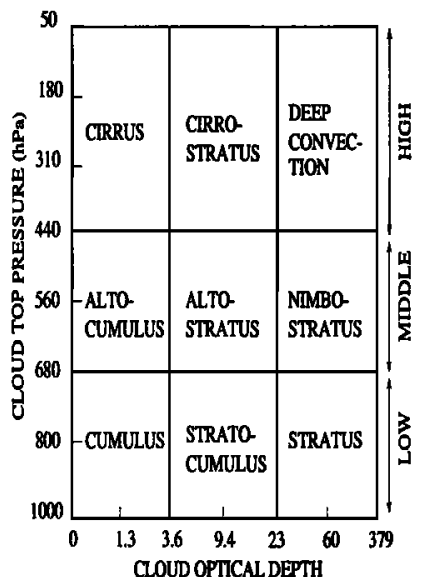

(b) ISCCP D
Figure 1. ISCCP C and D cloud types according to cloud top pressure (in $\mathrm{hPa}$ ) and cloud optical depth. 
Table 1. Global and hemispheric mean differences in cloud amount (\%) between the two cloud datasets (as ISCCP D1 - ISCCP C1).

\begin{tabular}{llllllll} 
& & \multicolumn{3}{c}{ January 1991 } & \multicolumn{3}{c}{ July 1990 } \\
\cline { 2 - 8 } Total & \multicolumn{3}{c}{ Ocean } & Land & Total & Ocean & Land \\
\hline \multirow{3}{*}{ Low } & Globe & 2.88 & 1.99 & 5.47 & 1.53 & 1.12 & 2.55 \\
& NH & 3.92 & 2.14 & 7.15 & 2.14 & 1.75 & 2.77 \\
& SH & 2.08 & 1.90 & 2.92 & 0.75 & 0.51 & 1.90 \\
\hline \multirow{3}{*}{ Mid } & Globe & 1.42 & 0.91 & 2.93 & 0.41 & 0.39 & 0.48 \\
& NH & 1.15 & 0.48 & 2.39 & 0.57 & 0.58 & 0.55 \\
& SH & 1.64 & 1.17 & 3.75 & 0.22 & 0.29 & 0.29 \\
\hline \multirow{3}{*}{ High } & Globe & 1.40 & 0.42 & 4.25 & 2.63 & 1.06 & 6.44 \\
& NH & 1.79 & 0.82 & 3.54 & 3.00 & 0.96 & 6.26 \\
& SH & 1.10 & 0.17 & 5.33 & 2.15 & 1.15 & 6.96 \\
\hline \multirow{3}{*}{ Total } & Globe & 5.71 & 3.32 & 12.66 & 4.58 & 2.56 & 9.47 \\
\multicolumn{2}{c}{ NH } & 6.86 & 3.44 & 13.09 & 5.71 & 3.28 & 9.57 \\
& SH & 4.82 & 3.24 & 12.00 & 3.11 & 1.86 & 9.15 \\
\hline
\end{tabular}

or altostratus cloud type from the former $\mathrm{C}$ nimbostratus cloud type. The cirrus cloud type is now limited to cloud optical depth lower than 3.6 to the benefit of the cirrostratus cloud type. Note that these cloud types do not necessarily correspond to the cloud types defined for visual surface inspection.

\section{Analysis Procedure}

We compare the C1 and D1 cloud products over a oneyear period, from April 1990 to March 1991. In the following, we consider only monthly means of the 3 hourly ISCCP $\mathrm{C} 1$ and D1 datasets and extract the cloud data at $15 \mathrm{~h}$ local (solar) time. The conversion from universal time to local time is done by selecting at every given location the closest observation in time. This allows a maximum coverage of the Earth's surface with both the VIS and IR radiances being available, but excludes the analysis of the wintertime cloudiness at high and polar latitudes. The data are further converted to an equal-angle grid with the resolution of $2.5^{\circ}$ in latitude by $2.5^{\circ}$ in longitude. For the discussion on cloud type, we limit ourselves to the months of July 1990 and January 1991.

\section{Global Cloud Cover}

Table 1 shows that the cloud amount is larger in the ISCCP D1 dataset by about $5 \%$, with the effect being much more pronounced over land (at about 9-13\%) than over ocean (at about 2-4\%). This tends to reduce the discrepancies between ISCCP C and surface cloud climatologies discussed by Rossow et al. [1993]. At least for July 1990 and January 1991, the increase in total cloudiness from C1 to D1 is larger over the Northern Hemisphere (NH) than over the Southern Hemisphere (SH), due mostly but not only to the correspondingly larger land fraction in the NH. The increase over the ocean is explained by an increase in low and middle level cloudiness and to a lesser extent by an increase in high level cloudiness (Fig. 2a). Over land, the large increase from $\mathrm{C} 1$ to $\mathrm{D} 1$ is due to correspondingly large increases in low and high level cloudiness and to a smaller increase in middle level cloudiness (Fig. 2b). One can note, however, that the partitioning of the cloud amount increase into low, middle, and high level cloudiness varies from month to month.

The latitude-time diagram of the zonally averaged low, middle, and high level cloud amounts are plotted in Fig. 3 for the ISCCP D1 dataset and for the difference between the two datasets. With few exceptions, these cloud amounts are larger in the ISCCP D1 than in the ISCCP C1 dataset whatever the latitude and month under consideration. The largest increases in low level cloudiness occur at high latitudes in summertime, over Eurasia when land is snowcovered from January to April, as well as over North Africa, the Arabic Peninsula and Iran. Regions of decrease in low level cloud amount include a latitudinal band centered at 50 to $60^{\circ} \mathrm{S}$ and Australia. The increase in middle level cloudiness is localized over Greenland and Antarctica, and over the continental high northern latitudes following the seasonal cycle of the snow cover. The increase in high level cloudiness occurs mostly over land, especially over the Western
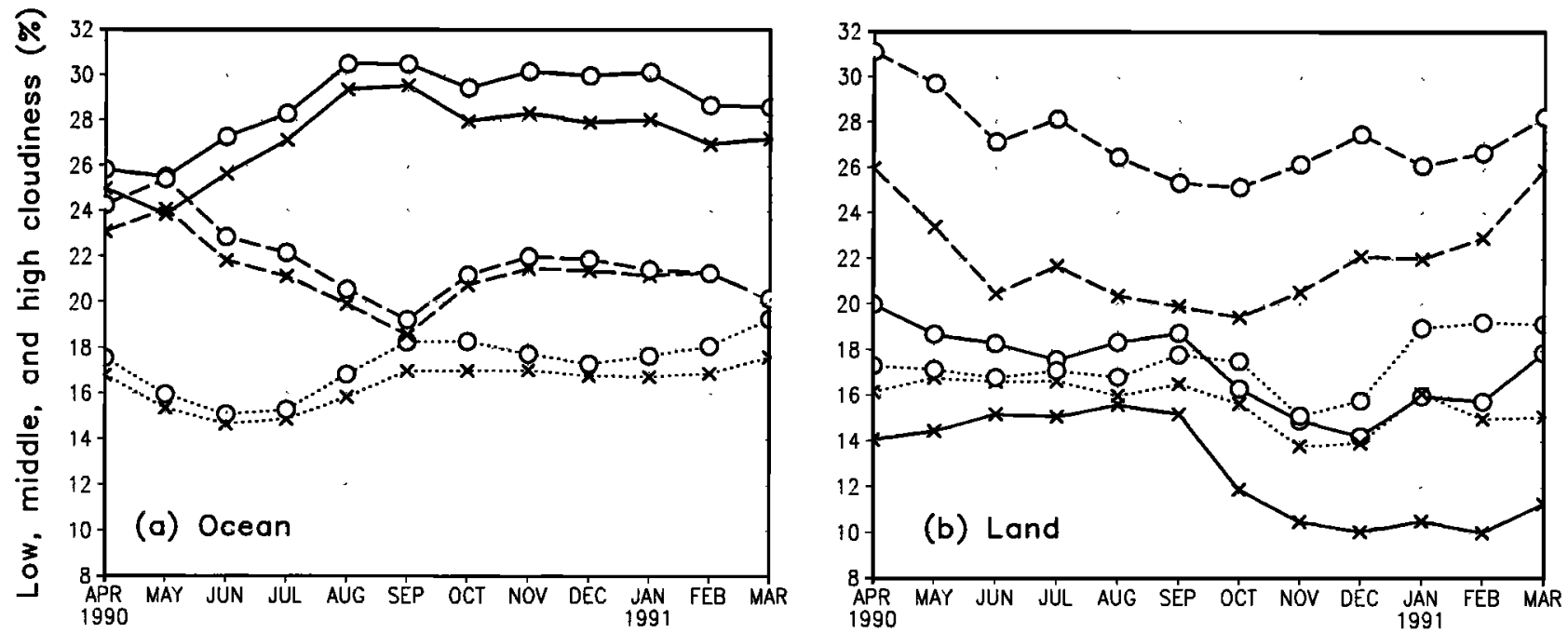

Figure 2. Seasonal cycle (April 1990 to March 1991) of the global-mean cloudiness (\%) at 15 hour local time. Open circles represent D1 data, crosses represent $\mathrm{C} 1$ data. Solid, dot, and longdash lines represents low, middle, and high level clouds, respectively. 

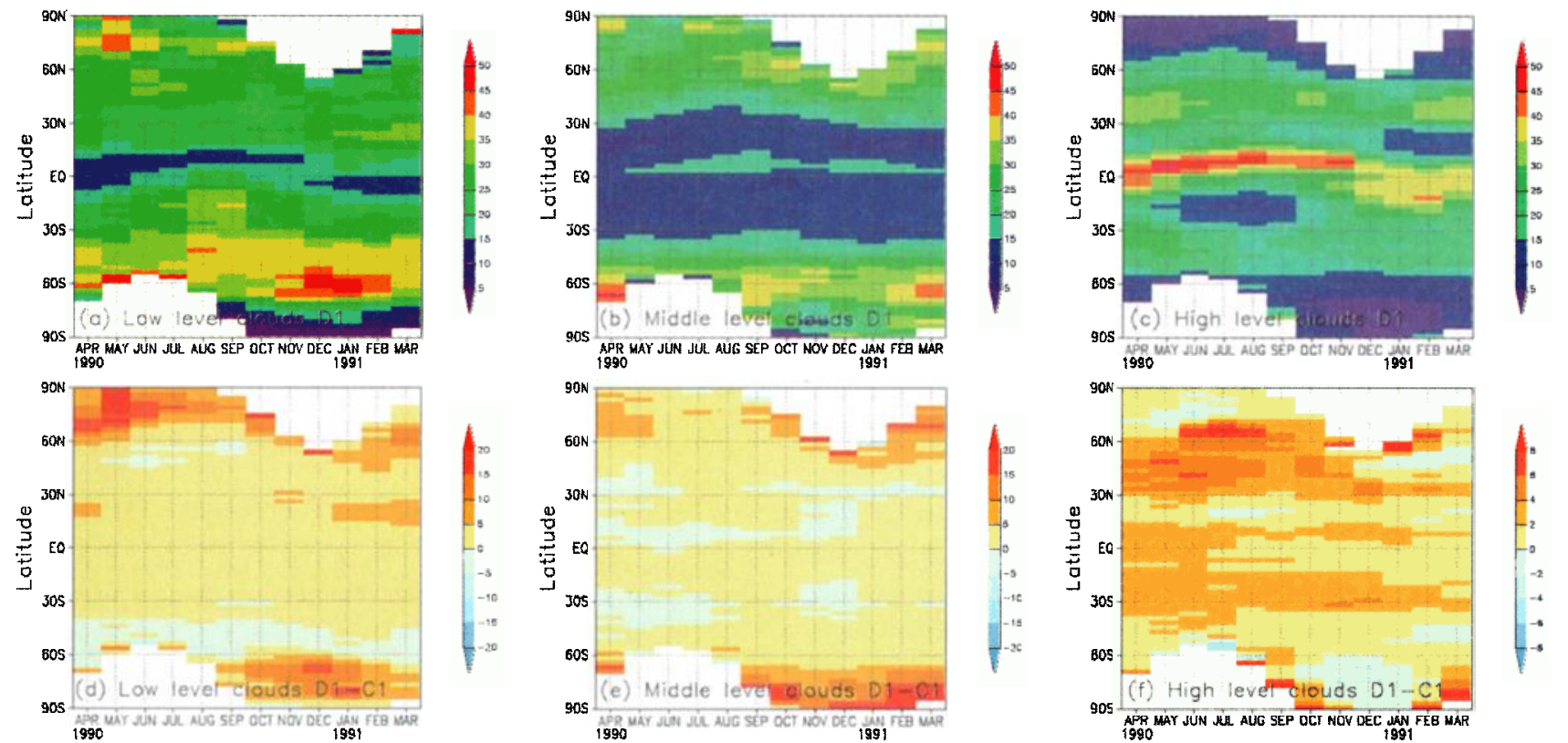

Figure 3. Seasonal cycle (April 1990 to March 1991) of the zonal mean low, middle, and high level cloudiness (\%) for ISCCP D1 cloud dadaset and for the difference between the two datasets (as ISCCP D1 - ISCCP C1).

North America, Asia, Australia, South America and South Africa, with however large seasonal variations.

\section{Cloud Types}

To circumvent the problem of cloud types having different definitions in the ISCCP C and D datasets, we project the $35 \mathrm{C} 1$ cloud classes into the nine cloud types of the D anal- ysis. Inversely, we also project the $42 \mathrm{D} 1$ cloud classes into the seven cloud types of the $\mathrm{C}$ analysis [Doutriaux-Boucher, 1997]. In the following, one color is attributed to each cloud type, where bluish, greenish, and reddish colors are for the low, middle, and high level clouds, respectively. We represent the cloud type information by filling each grid-box with the color code proportionally to the fraction of each cloud type, as done in Lau and Crane [1995]. Such a representation

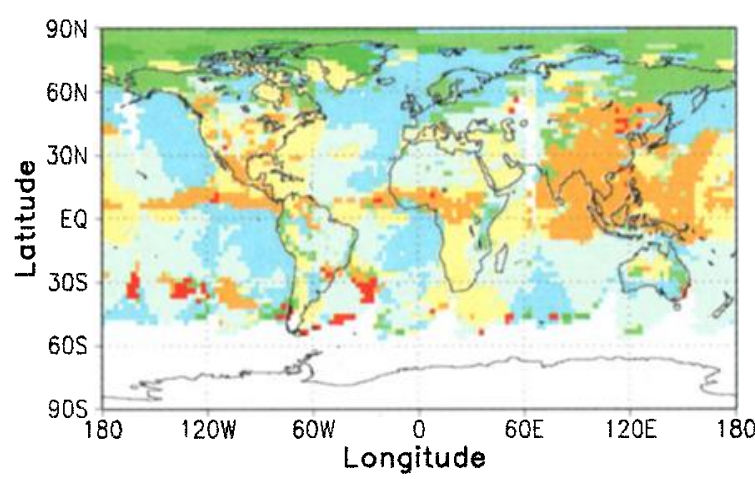

(a) July 1990 - ISCCP C1

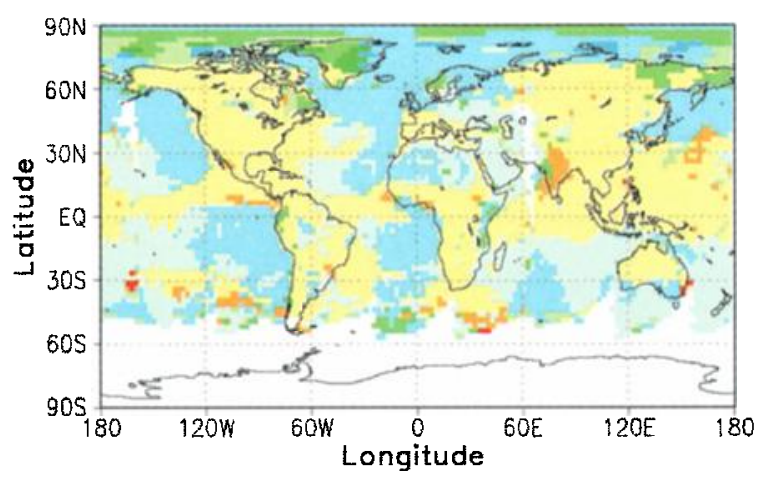

(c) July 1990 - ISCCP D1

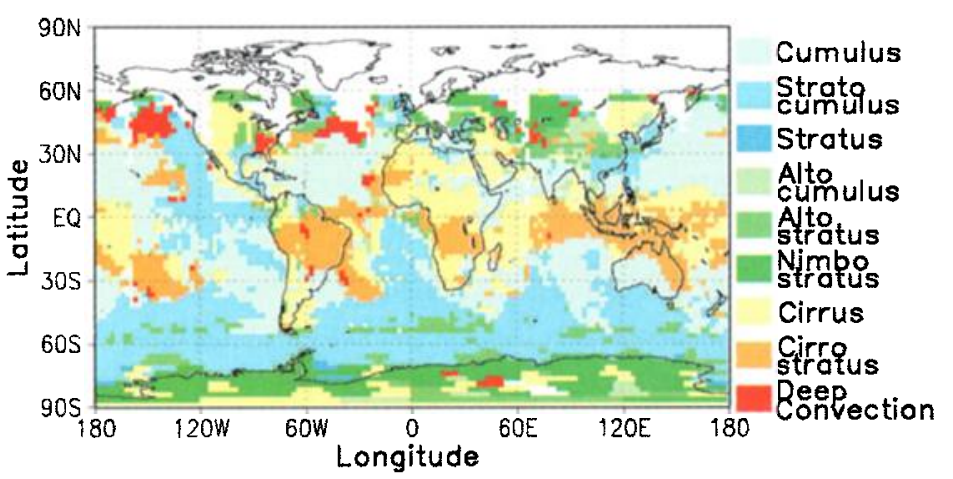

(b) January 1991 - ISCCP C1

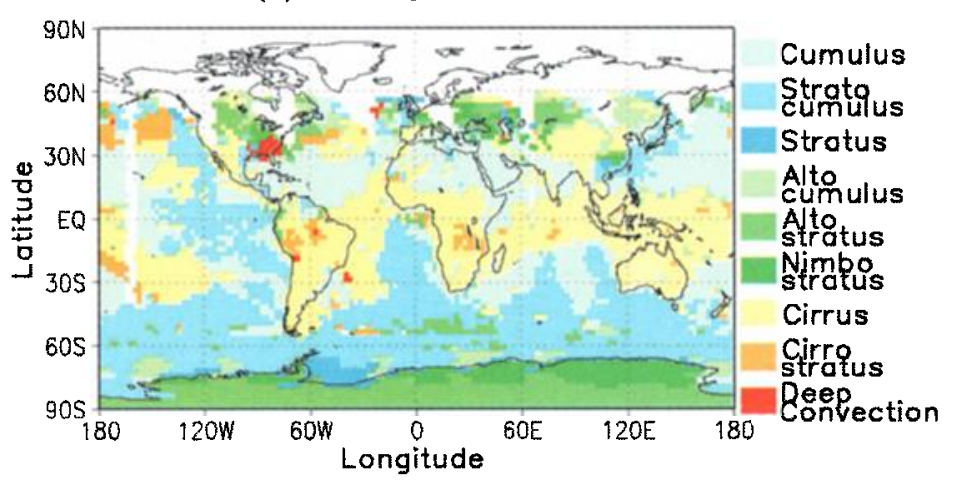

(d) January 1991 - ISCCP D1

Figure 4. Most frequent cloud type in the ISCCP C1 and ISCCP D1 cloud datasets for a, c) July 1990 and b, d) January 1991. 
reveals, at first sight, that the two cloud datasets show great similarity (maps not shown). The differences include a larger cloud cover at high latitudes in the ISCCP D1 dataset compared to ISCCP C1 (as discussed above) and larger cirrus amounts. Fig. 4 shows the most frequent cloud type (according to the ISCCP D definition) for both datasets and for the two months of July 1990 and January 1991. Note that clear sky is not considered here as a cloud type and that Fig. 4 does not provide any information at all on the cloud amount itself. It is evident from Fig. 4 that the ISCCP C1 dataset exhibits a much greater variety of dominant cloud types than ISCCP D1 does. In particular, the deep convection and cirrostratus cloud types almost disappear as dominant cloud types in the ISCCP D1 dataset. The stratus cloud type (in its ISCCP D definition) is the dominant cloud type at almost no location. On the contrary, the cirrus cloud type extends to many locations. Over some deserts, the most prevalent cloud type is a low level cloud in ISCCP D1 rather than a high level cloud in ISCCP C1, a feature which was also observed by Stubenrauch et al. [1998] using the ISCCP CX and DX datasets. This may be due to the inadequate identification of airborne dust as low level clouds, as suggested by the low values of effective droplet radii reported by Han et al. [1994] over these regions. Over the northern polar latitudes, the stratocumulus cloud type grows at the expense of the altostratus and nimbostratus cloud types. Over Antarctica, the most frequent cloud types is always a middle level cloud in ISCCP D1 in contrast to the ISCCP C1 where high level clouds were also found.

\section{Conclusion}

The ISCCP D algorithm predicts (1) more low level clouds, especially at high latitudes and over the deserts, (2) more middle level clouds, especially over Greenland and Antarctica, (3) more high level clouds, especially over the continents, compared to the ISCCP $\mathrm{C}$ version. This changes reduce the discrepancies found between the ISCCP C and other cloud climatologies. We also show that seasonal variations in the ISCCP D minus ISCCP C cloud amounts are large. There are important changes in the partitioning of the total cloud cover into the various ISCCP cloud types, calling for cautiousness when using a particular cloud type. Differences in the cloud diurnal cycle, as diagnosed by Kondragunta and Gruber [1994], between the ISCCP C and D datasets need to be investigated.

\section{References}

Brest, C. L., W. B. Rossow, and M. D. Roiter, Update of radiance calibrations for ISCCP, J. Atmos. Oceanic Technol., 14, 1091$1109,1997$.

Doutriaux-Boucher, M., La couverture nuageuse globale : comparaison d'observations, validation de modèles de cir- culation générale et simulation de nouvelles technologies d'observations, $\mathrm{Ph}$. D. thesis, $179 \mathrm{pp}$., Université Pierre et Marie Curie, [Available from Lab. Météorol. Dyn., Ecole Normale Supérieure, 24 rue Lhomond, 75231 Paris Cedex 05, France], 1997.

Han, Q., W. B. Rossow, and A. A. Lacis, Near-global survey of effective droplet radii in liquid water clouds using ISCCP data, J. Clim., 7, 465-497, 1994.

Klein, S. A., and D. L. Hartmann, Spurious changes in the ISCCP dataset, Geophys. Res. Lett., 20, 455-458, 1993.

Kondragunta, C. R., and A. Gruber, Diurnal variations of the ISCCP cloudiness, Geophys. Res. Lett., 21, 2015-2018, 1994.

Lau, N. C., and M. W. Crane, A satellite view of the synopticscale organisation of cloud properties in midlatitude and tropical circulation systems, Mon. Weather Rev., 123, 1984-2006, 1995.

Liao, X., W. B. Rossow, and D. Rind, Comparison between SAGE II and ISCCP high-level clouds, 1, Global and zonal mean cloud amounts, J. Geophys. Res., 100, 1121-1135, 1995

Rossow, W. B., and B. Cairns, Monitoring changes of clouds, Clim. Change, 31, 305-347, 1995.

Rossow, W. B., L. C. Garder, P. J. Lu, and A. W. Walker, International Satellite Cloud Climatology Project (ISCCP), Documentation of cloud data, Tech. Doc. WMO/TD 266, 76 pp. + append., World Meteorol. Org., Geneva, Switzerland, 1991.

Rossow, W. B., and R. A. Schiffer, ISCCP cloud data products, Bull. Amer. Meteor. Soc., 72, 2-20, 1991.

Rossow, W. B., A. W. Walker, D. E. Beuschel, and M. D. Roiter, International Satellite Cloud Climatology Project (ISCCP), Documentation of new cloud datasets, World Climate Research Programme (ICSU and WMO), Tech. Doc. WMO/TD 737, 115 pp., World Meteorol. Org., Geneva, Switzerland, [Available from ISCCP Global Processing Center, NASA GISS, 2880 Broadway, New York, NY 10025], 1996.

Rossow, W. B., A. W. Walker, and L. C. Garder, Comparison of ISCCP and other cloud amounts, J. Clim., 6, 2394-2418, 1993.

Schiffer, R. A., and W. B. Rossow, The International Satellite Cloud Climatology Project (ISCCP): The first project of the World Climate Research Program, Bull. Amer. Meteor. Soc., 64, 779-784, 1983.

Stubenrauch, C., W. B. Rossow, F. Chéruy, A. Chédin, and N. A. Scott, Clouds as seen by satellite sounders (3I) and imagers (ISCCP), I, Evaluation of cloud parameters, J. Clim., in press, 1998.

Wylie, D. P., and W. P. Menzel, Eight years of high cloud statistics using HIRS, J. Clim., in press, 1998.

M. Doutriaux-Boucher, Lab. d'Optique Atmosphérique, UFR de Physique, Université de Lille-I, 59655 Villeneuve d'Asca Cedex, France. (e-mail: mdoutri@loa.univ-lille1.fr)

G. Sèze, Lab. de Météorologie Dynamique du CNRS, Université Paris 6, Tour 15-25, 5ème étage, Case postale 99, 4 Place Jussieu, 75252 Paris Cedex 05, France. (e-mail: seze@lmd.jussieu.fr)

(Received June 12, 1998; revised September 14, 1998; accepted September 17, 1998.) 